\title{
Decarbonisation of Olefin Processes using Biomass Pyrolysis Oil
}

\author{
Sharifzadeh $\mathbf{M}^{a}{ }^{1}$, Wang $\mathbf{L}^{b}$ and Shah $\mathbf{N}^{a}$ \\ ${ }^{a}$ Centre for Process Systems Engineering (CPSE), Department of Chemical Engineering, Imperial College London. ${ }^{\mathrm{b}}$ Centre \\ for Environmental Policy, Imperial College London.
}

An imperative step toward decarbonisation of current industrial processes is to substitute their petroleum-derived feedstocks with biomass and biomass-derived feedstocks. For decarbonisation of the petrochemical industry, integrated catalytic processing of biomass pyrolysis oil (also known as bio-oil) is an enabling technology. This is because, under certain conditions, the reaction products form a mixture consisting of olefins and aromatics, which are very similar to the products of naphtha hydro-cracking in the conventional olefin processes. These synergies suggest that the catalytic bio-oil upgrading reactors can be seamlessly integrated to the subsequent separation network with minimal retrofitting costs. In addition, the integrated catalytic processing provides a high degree of flexibility for optimization of different products in response to market fluctuations. With the aim of assessing the techno-economic viability of this pathway, five scenarios in which different fractions of bio-oil (water soluble/ water insoluble) were processed with different degrees of hydrogenation were studied in the present research. The results showed that such a retrofit is not only economically viable, but also provides a high degree of flexibility to the process, and contributes to decarbonisation of olefin infrastructures. Up to $44 \%$ reductions in greenhouse gas emissions were observed in several scenarios. In addition, it was shown that hydrogen prices lower than $6 \$ / \mathrm{kg}$ will result in bio-based chemicals which are cheaper than equivalent petrochemicals. Alternatively, for higher hydrogen prices, it is possible to reform the water insoluble phase of bio-oil and produce bio-based chemicals, cheaper than petrochemical equivalents.

Keywords: Decarbonisation, Olefins, Biomass Pyrolysis Oil, Techno-economics, Life Cycle Assessment.

${ }^{1}$ Corresponding author, E-mail: mahdi@imperial.ac.uk; Tel:+44(0)7517853422. 


\section{Introduction}

Amongst major energy-users and GHG emitters, industrial processes are responsible for one third of the total worldwide energy consumptions and associated emissions. In addition, many industrial processes consume energy products as their feedstock. The main challenge is that industrial processes have long life cycles, in the order of decades, and the number of new processes which are being built is significantly smaller than the number of processes which are currently in use. These observations suggest that an important pathway toward decarbonisation of industrial processes is through retrofitting these processes. In particular, substituting petroleum-derived feedstocks with renewable feedstocks has substantial potential for mitigating the greenhouse gas (GHG) emissions and protecting the environment. However, most of the research in the field is focused on developing new processes which are subject to a high degree of uncertainty in sale-up and commercialization. The present paper explores the opportunity for substituting the naphtha feedstock in a conventional olefin process with biomass pyrolysis oil (also known as bio-oil). The research significance is due to the fact that the olefin process is highly energy-intensive and its products are essential for polymer production. Therefore, alternative production pathways have been under scrutiny [1-5].

The pathways for producing liquid fuels from biomass include fractionation, liquefaction, pyrolysis, hydrolysis, fermentation, and gasification [6], among which biomass pyrolysis provides the cheapest pathway toward renewable chemicals and fuel [7]. In principle, pyrolysis is the precursor of biomass gasification or combustion and refers to set of reactions occurring when biomass is heated in the absence of oxygen [6]. Nevertheless our knowledge of biomass pyrolysis is limited; Mettler, et al., [8] identified ten fundamental challenges in biomass pyrolysis with an emphasis on understanding the chemistry of conversion pathways, heat transfer phenomena and particle shrinkage. The diverse array of research into biomass pyrolysis include advanced analytical chemistry methods for bio-oil characterization [9-11], developing kinetic models for the pyrolysis reactions [12], computational fluid dynamic studies [13], design of new reactors [14], developing new heating methods such as microwave assisted pyrolysis [15,16], optimizing the bio-oil yield and process configuration [17], developing various bio-oil upgrading methods [18], process intensification [19], techno-economic analysis [20,21], environmental assessment [22], and enterprise-wide and supply chain optimization [23-25]. A recent review of the research into biomass fast pyrolysis has been published by Meier et al., [26].

Despite various economic incentives, biofuel commercialization poses an important challenge; the effluent of pyrolysis reactions, called bio-oil features undesirable properties such as chemical instability, high acidity, low heating value and immiscibility with petroleum-derived fuels. Therefore, upgrading bio-oil poses an important challenge. The conventional technologies for upgrading bio-oil include aqueous processing, hydrodeoxygenation (HYD), and zeolite cracking. The most common upgrading method is hydrotreatment upgrading of bio-oil which was originally inspired by similar 
processes for hydrodesulfurization (HDS) and hydrodenitrogenation (HDN) in petroleum refineries [27]. However, the amount of heteroatoms (i.e., oxygen) is an order of magnitude larger in the case of bio-oil. The implication of high oxygen content is excess coke formation. The resolution is multistage treatment in which firstly the bio-oil is stabilized in a low temperature reactor and then a deeper hydrodeoxygenation is accomplished in the second stage reactor at a higher temperature [28]. Here, we differentiate between char and coke. The former is a by-product of biomass pyrolysis, and is favored at relatively low temperature and low heating rate [29]. By contrast, the latter refers to the carbon atoms deposited on the catalysts surface of the upgrading reactors and is favored at low hydrogen partial pressures, [7, 30].

While hydrotreating does not alter the boiling range of hydrocarbons significantly, zeolite cracking is an efficient pathway to produce large qualities of light products by depolymerisation of heavy oligomers [31]. The challenge is that the coking can be so severe that a fixed bed reactor may become plugged quickly. Pretreatment using multi-stage hydrodeoxygenation can mitigate the problem [32]. In addition, fluidized bed reactors have the advantage that the coked catalyst can be regenerated and recycled to the reactor. Aqueous processing (also known as hydrothermal treatment) refers to a waterrich scenario at temperature above $200^{\circ} \mathrm{C}$, and a pressure sufficiently high to maintain the water at the near supercritical or supercritical state. It is widely observed that at these conditions water exhibits distinct processing advantages such as enhanced and tunable properties (e.g. solubility, solvent polarity, transport properties), and ease of solvent removal [33]. Other advantages of this technology include avoiding phase change and parasitic energy losses due to high pressure processing, versatile chemistry to existing chemical and fuel infrastructure, enhanced reaction rates [34], and minimal hydrogen consumption [35]. However, the engineering challenges include unknown reaction mechanisms, uncharacterized reaction pathways and severe processing conditions that the catalysts may not withstand.

Techno-economic performance of the fast pyrolysis pathway has been the focus of intensive research. Initial evaluations were made by research institutes. For example a detailed techno-economic analysis was conducted by Jones et al., [36] at Pacific North West National Laboratory (PNNL). The process consisted of a circulating fluidized bed pyrolysis reactor followed by two-stage hydrogenation reactors. Then, in a sequence of distillation columns, the stabilized bio-oil was resolved into biofuels with similar properties to naphtha and diesel. The heavy fraction was sent to a hydrocracker before recycling to the distillation columns. In this process, the hydrogen required for bio-oil hydrogenation and hydrocracking was produced through reforming natural gas. A technoeconomic comparison was made to the scenario where the process was co-located with a conventional refinery and the hydrogen was imported. Since the economy of bio-oil production is a strong function of hydrogen prices, Wright et al., [37] proposed a process in which, a fraction of bio-oil was partially reformed to produce the required hydrogen for upgrading the remaining bio-oil. They concluded that producing hydrogen 
from bio-oil itself is more profitable compared to purchasing hydrogen. Recently, Shemfe, et al., [38] studied the technoeconomic performance of fast pyrolysis for cogeneration of biofuel and electricity power. A merit of this study was incorporation of rate-based chemical reactions for modelling the hydroprocessing section. In parallel, technoeconomic analysis of producing commodity products through catalytic upgrading the bio-oil has been the focus of several researchers. Vispute, et al., [7] showed that the annual economic potential (EP) of this pathway strongly depends on the hydrogen price. Later, Brown, et al., [39] conducted a more detailed techno-economic analysis. They identified the biomass pyrolysis yield as an important factor in economic viability of this technology. Later, Zhang et al., [40] compared the biofuel pathway with the commodity chemical pathway. They concluded that a scenario where the required hydrogen is produced through natural gas reforming is the most economic option. All the aforementioned studies applied simplified process flowsheeting sufficient for calculating overall mass balances and did not include the sophisticated separation network required for resolving the highly complex olefin-aromatic mixture into marketable high purity products. The present research extends the previous studies by adapting the catalytic upgrading technology for retrofitting existing olefin process and evaluates the opportunity for decarbonisation of olefin industries through substitution of their conventional petroleum feedstocks (e.g., naphtha) using the renewable pyrolysis bio-oil. The present analysis is comprehensive and includes technoeconomic as well as environmental life cycle assessments.

Recently, Vispute, et. al, [7] developed a reaction network for upgrading bio-oil which combines the advantages of all three aforementioned technologies in order to produce an array of olefin and aromatic products as a fungible feedstocks for existing refinery and petrochemical infrastructure. In their proposed reaction network, firstly the thermal stability and hydrogen content of the bio-oil is improved and then using a suitable zeolite catalyst with the desirable pore size and active sites, it is converted to primary olefins and aromatic products. Another advantage of this methodology is that due to thermal stabilization and hydrogenation at low temperatures, coke generation is minimized and the overall carbon efficiency is as high as $60 \%$. In addition, the multi-stage processing provides a high degree of flexibility to optimize the yield of products. In their proposed scheme, the reaction network consists of three reactors which provide alternative routes for upgrading and enables optimization of the product properties and carbon yields as well as the hydrogen consumption. Firstly, the crude biooil is mixed with water at a mass ratio of four units of water per a unit of the crude-bio-oil. Then, the mixture is phase separated in a decanter. The aqueous phase, also called water soluble bio-oil (WSBO), is sent to a low-temperature hydro-processing unit which operates at $398 \mathrm{~K}$ and 100 bar. This is the highest temperature with no risk of catalyst coking and reactor plugging. Supported Ru was identified as the most active and selective catalyst for aqueous phase hydro-processing. The partially stabilized bio-oil is then fed to the second hydrogenation stage which operates at $523 \mathrm{~K}$ and 100 bar. Supported Pt was identified as the best catalyst for this stage with desirable properties such 
as high $\mathrm{C}-\mathrm{O}$ hydrogenation and low $\mathrm{C}-\mathrm{C}$ bond cleavage activities. The third reactor provides an upgrading step over the zeolite catalyst in order to produce olefins and aromatics. Vispute et. al., [7] demonstrated that the overall yields of the aromatic and olefin products depends on the extents of the added hydrogen in the first two stages and therefore the reaction network will provide the option for optimization of the products yields. In the present research, similar to Vispute, et. al, [7], five scenarios were studied and compared:

Scenario (1): the whole bio-oil (WSBO+WIBO) is directly sent to the zeolite upgrading stage;

Scenario (2): the whole bio-oil (WSBO+WIBO) is firstly hydrotreated in a low temperature reactor and then processed in the zeolite upgrading reactor;

Scenario (3: water soluble bio-oil (WSBO) is sent directly to the zeolite upgrading stage;

Scenario (4): water soluble bio-oil (WSBO) is firstly hydrotreated in a low temperature reactor and then processed in the zeolite upgrading reactor;

Scenario (5): only water soluble bio-oil (WSBO) is processed in all the three hydrotreating and upgrading reactors.

In scenarios 3-5, the water insoluble bio-oil (WIBO) is sold as a low quality fuel product (half of the coal price [39]). However, considering the sensitivity of the process to the hydrogen price, an additional scenario was studied, which is equivalent to the fifth scenario but the water insoluble biooil is reformed to produce the required hydrogen. The remaining sections of this paper are organized as follows. Firstly the synergies and integration opportunities between the integrated catalytic process of bio-oil and the conventional olefin processes are discussed. The next section will evaluate the flexibility of integrated catalytic processing in optimizing the yields of various products. These discussions will enable proposing the bio-oil as a substitute feedstock for existing olefin infrastructures. The rest of the paper will focus on the evaluating alternative process configurations for integrated catalytic processing of bio-oil with respect to economic and environmental measures. Finally the paper will conclude with discussions and suggestions for future research. It is notable that the detailed process flow diagrams and experimental data used for process modelling are summarized in the enclosed Electronic Supplementary Materials (ESM).

\section{Methodology and approach}

The following sections report the methods employed for process design, economic evaluation and life cycle analysis. The features of interest are adapting the process configuration to the new biomassderived feedstock, evaluating process flexibility, the applied approach for economic analysis and the method for the environmental impact assessments.

\subsection{Retrofitting existing olefin processes for biomass feedstock}


The products of integrated catalytic processing of pyrolysis bio-oil are a mixture consisting of olefins and aromatics, which is very similar to the effluent of naphtha hydro-cracking in the conventional olefin processes. Similarities and differences between the effluents of the bio-oil upgrading process and the effluents of naphtha hydrocracking are shown in Table 1. This table reveals an important difference; the bio-oil pathway produces significantly larger amount of carbon dioxide compared to the naphtha pathway. This is the implication of biomass chemistry. For example, hybrid poplar has more than $41 \%$ (mass basis) oxygen content [41] and the carbon oxides are produced from oxygenates through upgrading reactions. Table 1 also suggests that the two processes have eleven common components from which seven components are the main products of both processes. However, the conventional naphtha hydrocracking process produces a minor fraction of olefins with higher $(\geq 3)$ number of unsaturated bonds. These highly active components conventionally are not separated, but saturated in hot and cold sections. The following subsections examine if an existing olefin process can be retrofitted to substitute naphtha by bio-oil.

The block diagram of a conventional olefin process is shown in Fig. 1.a. The process consists of three main sections: hot section, cold section, and pyrolysis gasoline hydrogenation (PGH) section. In the hot section, the naphtha feedstock is mixed with water and fed to high temperature reactors (several parallel furnaces) where it is converted to a mixture of olefins, aromatics and heavy components, called Cracked Gas (Tables 1). This mixture is quickly quenched and the large amount of inert water and heavy hydrocarbons are separated using distillation columns. The water is stripped from light gases and recycled to the furnaces. The cleaned cracked gas is sent to an energy induced separation network, comprising a large-scale multi-stage compressor and a stripper [42]. The aim of cracked gas compression is to elevate the required temperatures for cryogenic distillation of light products. The compressed mixture of olefin products is dried and sent to a cryogenic distillation train (i.e., cold section) where it is resolved to pure components. In parallel, as a result of sequential compression and cooling of the cracked gas, most of the aromatic components condense which after stripping the dissolved gases, are sent to the PGH section. The aromatic mixture has properties very similar to gasoline. However, it also contains highly reactive dissolved olefins which if stored unsaturated, will result in polymerization and degradation of the gasoline. Therefore, the aromatic mixture is firstly saturated using hydrogenation reactors and then sent to a distillation train where it is resolved to various hydrocarbon cuts. A more detailed description of the naphtha-based olefin process can be found in the literature [43].

Table 1. Comparison between the effluents of naphtha hydrocracking (Cracked Gas) and integrated upgrading of bio-oil (Scenario 5) - mass fraction (dry basis).

\begin{tabular}{lll} 
& Cracked Gas [42] & Scenario 5 [7] \\
\hline Hydrogen & 0.0115 & \\
\hline Cox & $\mathbf{0 . 0 0 0 2}$ & $\mathbf{0 . 2 3 5 1}$ \\
\hline $\mathrm{CO}$ & 0.0001 & 0.1010 \\
$\mathrm{CO}_{2}$ & 0.0001 & 0.1341 \\
Coke & & 0.0941
\end{tabular}




\begin{tabular}{lll} 
H2S & 0.0004 & \\
\hline C1 to C4 Alkanes & $\mathbf{0 . 2 7 4 1}$ & $\mathbf{0 . 1 4 0 6}$ \\
\hline Methane & 0.1738 & 0.0374 \\
Ethane & 0.0608 & 0.0351 \\
Propane & 0.0053 & 0.0343 \\
Butane & 0.0029 & 0.0339 \\
Pentane & 0.0261 & \\
Hexane & 0.0052 & \\
Heptane & 0.0005 & \\
\hline Olefins (double bonds) & $\mathbf{0 . 5 0 6 9}$ & $\mathbf{0 . 3 7 5 1}$ \\
\hline Ethylene & 0.3507 & 0.1200 \\
Propylene & 0.1277 & 0.2018 \\
Butylene & 0.0285 & 0.0533 \\
\hline Olefins (triple bonds) & $\mathbf{0 . 0 6 0 1}$ & $\mathbf{0 . 0 0 0 0}$ \\
\hline Acetylene & 0.0086 & \\
13-Butadiene & 0.0402 & \\
Propadiene + M-Acetylene & 0.0113 & \\
C4 Acetylene & 0.0020 & \\
\hline Aromatics & $\mathbf{0 . 1 0 6 0}$ & $\mathbf{0 . 1 4 8 1}$ \\
\hline Benzene & 0.0685 & 0.0400 \\
Toluene & 0.0208 & 0.0738 \\
Styrene & 0.0122 & 0.0019 \\
Xylene + E-Benzene & 0.0045 & 0.0323 \\
\hline Heavy Ends & $\mathbf{0 . 0 3 8 2}$ & $\mathbf{0 . 0 0 7 0}$ \\
\hline C9- & 0.0082 & \\
C10+ & 0.0300 & 0.0007 \\
Indene & & 0.0007 \\
Naphthalene & & 0.0055 \\
unidentified & & \\
\hline & & \\
\hline & & \\
\hline
\end{tabular}

Fig. 1.b shows the retrofitted process including the additional processing steps. Biomass is firstly sent to the pyrolysis section where it is converted to light gases, condensable hydrocarbons and coke. Unfortunately, the hydrocarbon condensates, called bio-oil, suffer from some undesirable properties such as high oxygen content, low energy content and immiscibility with petroleum-derived fuels. Therefore, the bio-oil product is sent to the next section for upgrading. As discussed earlier, this section consists of three reactors, a low temperature hydrogenation reactor, a high temperature hydrogenation reactor, and a zeolite upgrading reactor. The effluent of this section is a highly complex mixture of carbon oxides, water, olefins and aromatics, which is sent to separation sections. The aforementioned similarities between the effluents of the integrated upgrading process and the naphtha-derived cracked gas suggest that the separation sections 300-600 are very similar. More details of the retrofitted process including process flow diagrams and detailed process description are presented in the Electronic Supplementary Material (ESM). 

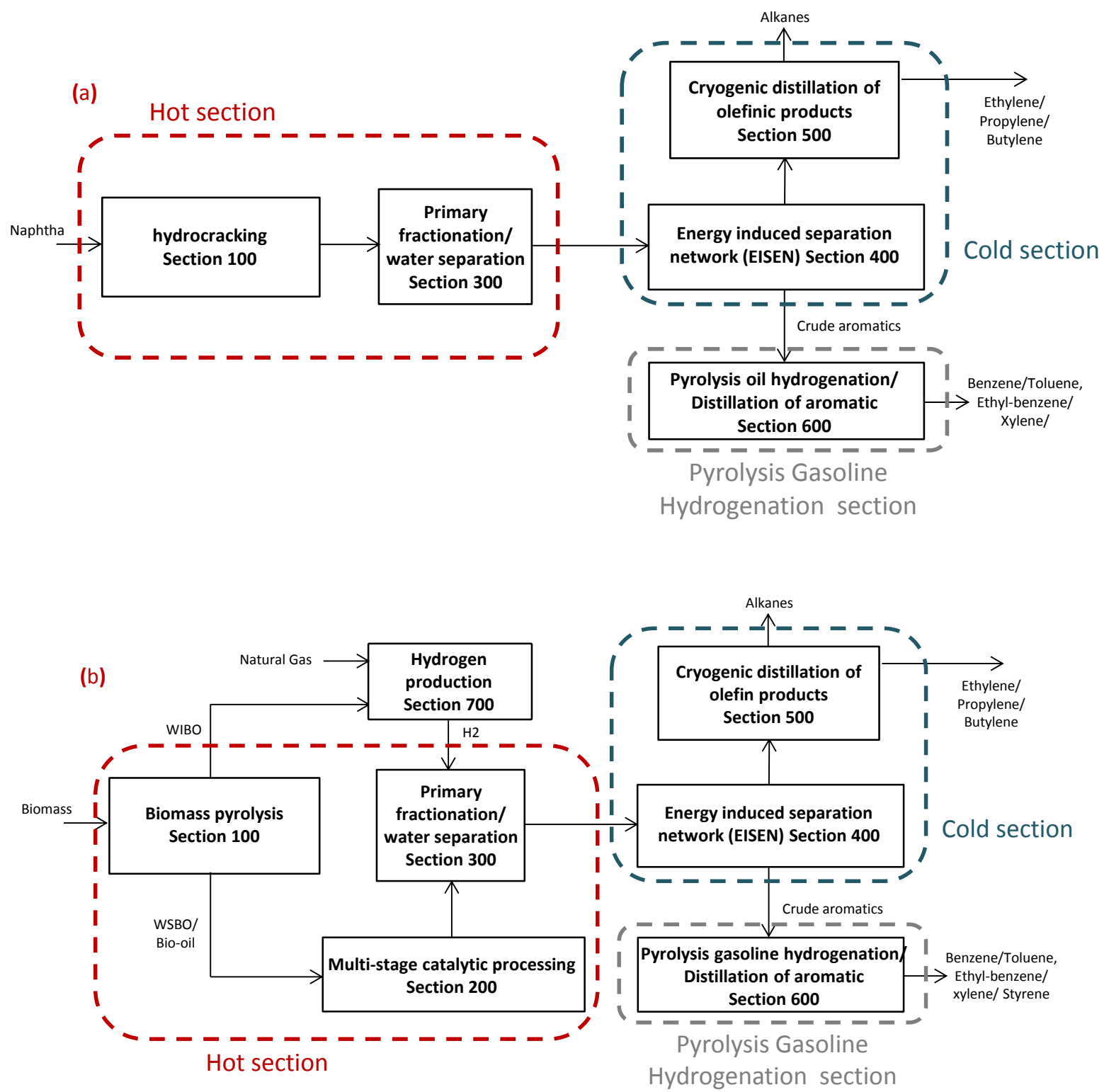

Fig. 1. Process block diagrams for (a) conventional olefin process, (b) the retrofitted process using biomass

There are three minor differences between the separation sections of process (a) and (b). Firstly, the amount of carbon dioxide is larger in bio-mass derived bio-cracked gas. Therefore, the $\mathrm{CO}_{2}$ scrubber (see ESM for more details) should be retrofitted to handle larger amounts of $\mathrm{CO}_{2}$. Secondly, conventional cracking gas contains a fraction of olefins with a higher number of unsaturated bonds. Due to the small amounts of these products they are often dealt as impurities and are saturated by hydrogenation reactions. Since these components were not observed by Vispute et. al., [7], the corresponding equipment can be retired. Finally, the conventional cracked gas contains a large amount of hydrogen which can be separated as a by-product in pressure swing adsorption (PSA) columns. However, the biomass-based process is a net consumer of hydrogen due to the presence of oxygenates.

\subsection{Process modelling}


The process modelling was conducted using Aspen Plus ${ }^{\mathrm{TM}}$ simulator. The pyrolysis and upgrading reactors were modelled based on the yield data by Vispute, et. al., [7] and Jones, et al., [36]. High purity chemicals were produced (> 0.99 mass fraction). ENRTL-RK method described the thermodynamic properties. The simulation of pyrolysis section was validated using data from [36]. The model of the cryogenic section was validated using the data from Sharifzadeh et al.'s study [42]. The distillation columns were modelled using RADFRAC unit operation in Aspen Plus. The pressure swing adsorption was modelled using "SEP" unit operation in Aspen Plus, assuming 90\% separation efficiency. The water soluble bio-oil fraction is reported to comprise $60-80 \%$ of the total oil, on the mass basis [44]. In the present study, the conservative value of $62 \%$ was adapted from [45].

Table 2. The modelling approach and operating conditions for major reactors.

\begin{tabular}{|c|c|c|c|c|c|}
\hline Reactor & Description & $\mathbf{T}(\mathbf{K})$ & $\mathbf{P}$ (bara) & Modelling approach & Ref. \\
\hline R101 (Fig S1) ${ }^{a}$ & Pyrolysis reactor & 773 & 1.08 & Yield & [36] \\
\hline R201 (Fig S2) ${ }^{a}$ & $\begin{array}{l}\text { Low temperature hydrogenation } \\
\text { reactor }\end{array}$ & 398 & 100 & Yield & [7] \\
\hline R202 (Fig S2) ${ }^{a}$ & $\begin{array}{l}\text { High temperature hydrogenation } \\
\text { reactor }\end{array}$ & 523 & 100 & Yield & [7] \\
\hline R203 (Fig S2) ${ }^{a}$ & Zeolite cracking reactor & 873 & 1.01 & Yield & [7] \\
\hline R601 (Fig S5) ${ }^{a}$ & $\begin{array}{l}\text { Pyrolysis gasoline } \\
\text { hydrogenation reactor }\end{array}$ & 433 & 27 & $\begin{array}{l}\text { Conversion }(100 \% \\
\text { olefins) }\end{array}$ & - \\
\hline R701 (Fig S6) ${ }^{a}$ & Reformer reactor & 1123 & 25.8 & Chemical Equilibrium & [36] \\
\hline R-702 (Fig S6) ${ }^{a}$ & $\begin{array}{l}\text { High temperature gas shift } \\
\text { reactor }\end{array}$ & 626 & 24.8 & Conversion $(80 \% \mathrm{CO})$ & [36] \\
\hline
\end{tabular}

(a) Please refer to the Electronic Supplementary Material (ESM) for the process flow diagrams, Figs. S1,S2,S5,S6.

Table 2 reports the modelling approach and operating conditions applied for simulating the main reactors. The pyrolysis reactor was modelled using the yield data from a previous study by DOE [36]. The compositions and flowrates of the pyrolysis reactor feed and products are shown in Table S4ESM. The integrated catalytic reactors were modelled using the experimental yield data from Vispute et al.'s study [7]. The elemental analysis used for modelling water soluble bio-oil (WSBO) and water insoluble bio-oil (WIBO) were from [45] and are shown in Table S5. The product compositions of the low temperature hydrogenation reactor (R-201 in Fig S2) and the high temperature hydrogenation reactor (R-202 in Fig S2) are shown in Table S5-ESM. Table S1 shows the product compositions and flowrates of the zeolite cracking reactor (R-203 in Fig S2-ESM) in different scenarios (1-5), adapted from [7]. The experimental results from [7] were reported in terms of identified carbon contents and were converted to mass and mole fractions using molecular weight and molecular formula of each component. Table S1-ESM reports the amount of required hydrogen in each Scenario (1-5), [7]. The pyrolysis gasoline hydrogenation reactor was modelled based on $100 \%$ conversion of olefins. The required amount of hydrogen was calculated based on the amount unsaturated carbon in the reactor feed. The reformer (R-601 in Figure S5-ESM) was modelled based on chemical equilibrium using Gibbs free energy minimization [49]. The high temperature gas shift reactor was modelled based on $80 \%$ of conversion of CO though water gas shift reaction [36]. The costs of conventional unit 
operations (e.g., distillations, compressors) were evaluated using Aspen Economic Analyzer ${ }^{\mathrm{TM}}$. The costs of nonconventional unit operations (e.g., reformer, pyrolyzer) were calculated by scaling with respect to economic data from [36].

\subsection{Process flexibility}

Another key feature of process design and retrofitting is to ensure flexibility of the process in response to fluctuation in the demand and the prices of products. In the present research, a yield-based optimization was formulated to study different scenarios in which the carbon content of each product stream is maximized. To this end, the superstructure of the integrated upgrading reactors was constructed, as shown in Fig. 2. Table 3 suggests that by adjusting Valves 201-205, it is possible to optimize the amount of feed to each reactor, and hence the product yields. For example, the configuration in which Valve 201 is open and other valves are closed corresponds to Scenario (1). The arrangements of valves are similar in Scenarios 5 and $5 \mathrm{w} /$ reformer. The difference is that in Scenario $5 \mathrm{w} /$ reformer, water insoluble bio-oil is used for hydrogen production, but in Scenario 5, it is sold.

Fig. 3 shows the results of flexibility optimization. This figure suggests that the process can be optimized toward generation of various products with a high degree of flexibility. For example, Scenario 5 is well posed to maximize the yield of olefin products. However, Scenario 2 is more appropriate for producing aromatics. By comparison, Scenario 1 produces heavier products. In practice, the designer may desire to include all the three reactors and oversized them so the yields of different products can be optimized in real-time. An interesting observation was that the optimizer chose between Scenarios (1-5) and not a combination of them, implying that the reactor temperatures (hence the product yields) are well posed for optimizing different product cuts.

Table 3. The position of valves in Fig. 2 for different upgrading scenarios

\begin{tabular}{lllllll}
\hline & SC1 $^{\text {(a) }}$ & SC 2 & SC 3 & SC 4 & SC 5 & SC 5 w/ reformer \\
\hline Valve-201 & Open & Open & Close & Close & Close & Close \\
Valve-202 & Close & Close & Open & Open & Open & Open \\
Valve-203 & Close & Open & Close & Open & Open & Open \\
Valve-204 & Close & Close & Close & Close & Open & Open \\
Valve-205 & Close & Close & Close & Open & Close & Close \\
\hline
\end{tabular}

(a) SC1 refers to Scenario 1 


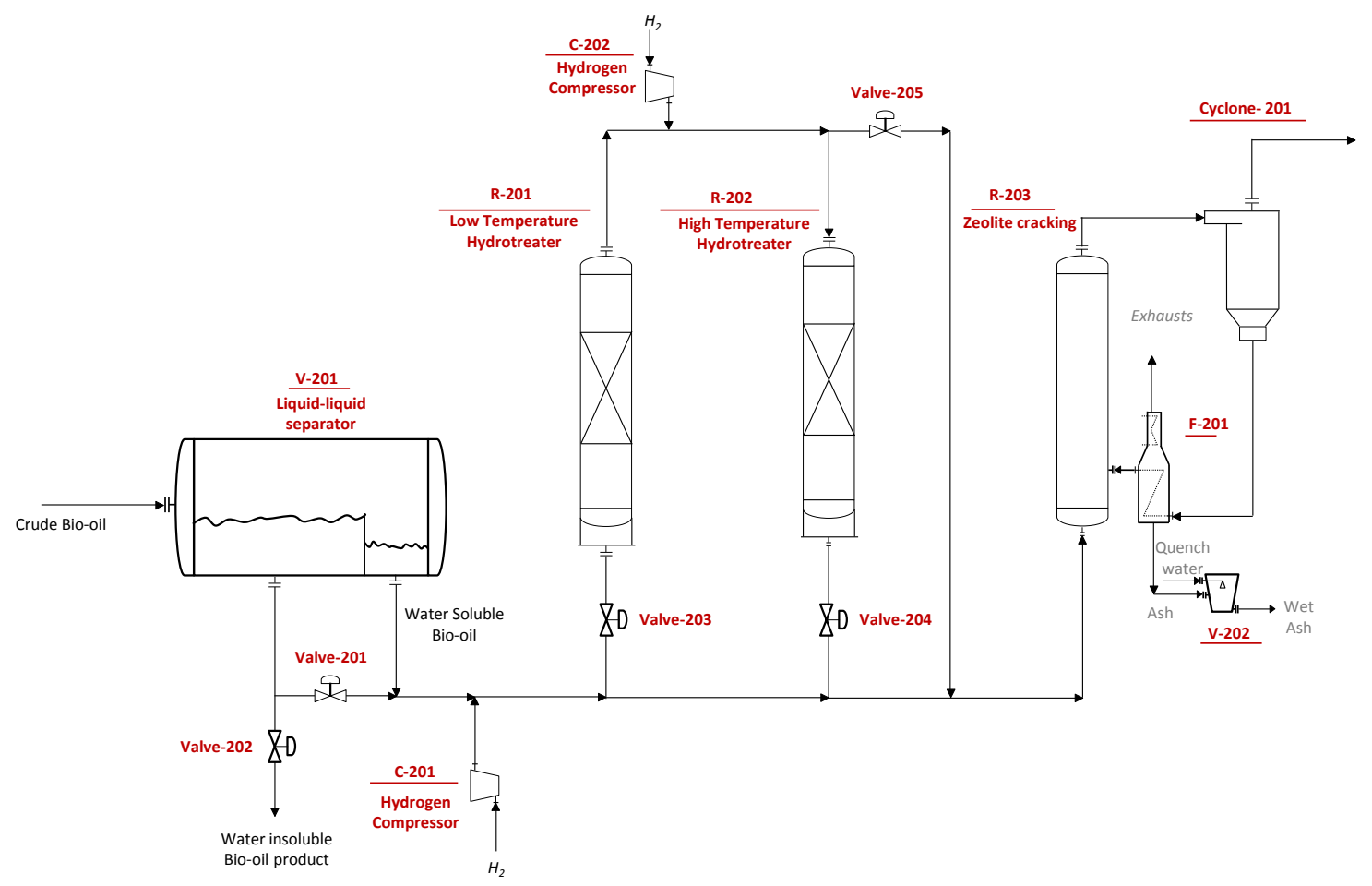

Fig. 2. Integrated catalytic upgrading of bio-oil: adjusting Valves 201-204 allows optimization of the product yields

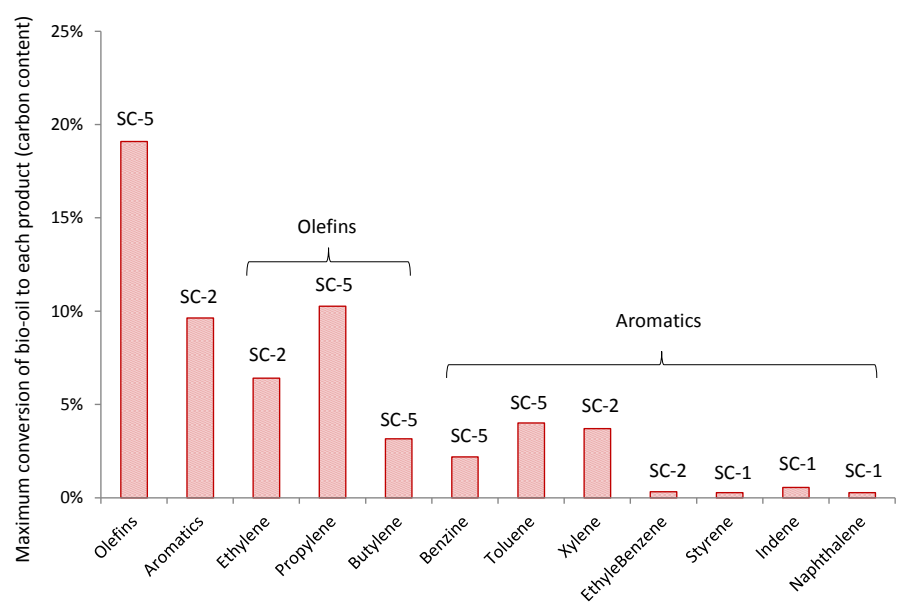

Fig. 3. The result of flexibility optimization: the maximum carbon conversion to each product 


\subsection{Economic evaluation}

\subsubsection{Cost estimation}

It is assumed that the plant is an Nth plant and located in the US. In order to identify the most economic process configuration, two approaches were utilized. They are net present value (NPV) and minimum product selling price (MPSP). NPVs were applied for comparing the economy of Scenarios (1-5) and studying the sensitivity of economic feasibility with respect to hydrogen price. MPSPs were applied for comparison with naphtha-derived products. The NPVs of all the scenarios were evaluated based on the data from process simulator. For the case of conventional process equipment (such as distillation, vessels, compressors, cyclone, etc.), the purchased and installed equipment costs were calculated using Aspen Economic Analyzer ${ }^{\mathrm{TM}}$. However costing of nonconventional equipment (e.g., reformer) was conducted by scaling up/down according to the following relation and with reference to the economic data from literature [37]:

$$
\text { New cost }=\text { Base cost } *\left(\frac{\text { New size }}{\text { Base size }}\right)^{f_{\text {scale }}}
$$

Once the total purchased equipment costs (TPEC) are estimated, the total indirect costs (TIC) are calculated including engineering (32\% of TPEC), construction (34\% of TPEC), legal and contractors fees (23\% of TPEC) and project contingency (37\% of TPEC). The fixed capital investment (FCI) is the sum of Total Direct Installed Costs (TDC) and TIC. The total capital costs include FCI and land cost (6\% of TPEC) and the working capital (5\% FCI) (Jones et al. 2009). The variable operating costs including raw materials, utilities, and waste disposal charges are summarized in Table 4. The fixed operating costs including labor, overheads (95\% of labor cost), maintenance (4\% of TCI), and insurance (4\% of TCI) are scaled up based on Philipp, et al.'s study [46].

Table 4. Summary of variable operating cost

\begin{tabular}{lll}
\hline Materials/Chemicals/Utilities & Cost & Reference \\
\hline Hybrid poplar & $50.07[\$ /$ short ton $]$ & {$[36]$} \\
Natural gas & $3.89[\$ / 1000 \mathrm{scf}]$ & {$[47]$} \\
Catalyst $(\mathbf{R u} / \mathbf{C})$ & $5.6[\$ / \mathrm{kg}]$ & {$[39]$} \\
Catalyst $(\mathbf{P t} / \mathbf{C})$ & $56.29[\$ / \mathrm{kg}]$ & {$[39]$} \\
Catalyst $(\mathbf{Z e o l i t e})$ & $1.6[\$ / \mathrm{kg}]$ & {$[39]$} \\
Fresh water & $0.05[\$ / 1000$ gallon $]$ & {$[49]$} \\
Electricity & $37.02[\$ / \mathrm{MWh}]$ & {$[48]$} \\
Disposal of ash & $18[\$ / \mathrm{short} \mathrm{ton}]$ & {$[36]$} \\
Steam & $4.3 \times 10^{-3}-4.5 \times 10^{-3}[\$ / \mathrm{kg}]^{\mathrm{a}}$ & {$[49]$} \\
Refrigerant & $1.08 \times 10^{-5}-4.51 \times 10^{-5}[\$ / \mathrm{kg}]^{\mathrm{b}}$ & {$[49]$} \\
Cooling water & $4.43 \times 10^{-6} \$ / \mathrm{kg}$ & {$[49]$} \\
\hline
\end{tabular}

Note: ${ }^{a}$ varied for steam with different pressures; ${ }^{b}$ varied for different types of refrigerants.

\subsubsection{Discounted cash flow method}


The NPVs were calculated using a discounted cash flow method (10\% discount rate) for a period of 20 years, which is the assumed plant lifetime. The plant was assumed to be $100 \%$ equity [46] with 2.5 years as a construction period and 6 months as the start-up time [36]. Prices of the products are summarized in Table 5. All costs in this study were indexed to the reference year of 2012 and the NPV of the project is reported as 2012 USD. The MPSPs is calculated using a discounted cash flow analysis and refers the product price at which the net present value of the project is zero at a set discounted rate of $10 \%$. Since the process produces an array of olefins and aromatics, the MPSP for each product was estimated regarding to their ratio to the reference product (Ethylene in our study). These ratios were calculated based on their market prices (Table 5).

Table 5. Summary of the price of the petroleum-derived products

\begin{tabular}{lll}
\hline Bio-based chemicals & Price $[\mathbf{\$} / \mathbf{k g}]$ & Reference \\
\hline Ethane & 0.45 & {$[50]$} \\
Benzene & 0.85 & {$[39]$} \\
Toluene & 0.71 & {$[39]$} \\
Butylene & 0.75 & {$[39]$} \\
Ethylene & 1.49 & {$[39]$} \\
Propylene & 1.58 & {$[39]$} \\
Propane & 1.55 & {$[51]$} \\
Butane & 0.88 & {$[51]$} \\
Indene+ Naphthalene, & 0.85 & {$[39]$} \\
Ethyl benzene+ Styrene+ Xylene & 1.12 (average) & {$[39]$} \\
WIBO & 0.02 & {$[39]$} \\
\hline
\end{tabular}

\subsection{Life Cycle Analysis for GHG emissions calculation}

Life Cycle Analysis (LCA) approach was applied to calculate the GHG emissions for bio-based products through their 'Cradle-to-Grave' life cycles. The function unit is defined as ' $1 \mathrm{~kg}$ bio-based chemical product'. The whole life cycle includes feedstock cultivation (hybrid poplar), production of bio-based chemicals in biorefinery, transportation (raw materials, intermediate products, and final products), and end use of bio-based chemicals. The inventory data for hybrid poplar cultivation are adopted from Gasol et al.'s study [52] and the mass balance including chemical utilization and energy demand in bio-based chemicals production process are obtained from ASPEN Plus process simulations. The GHG emission factors for inputs in hybrid poplar cultivation, bio-based chemicals production, and transportation are taken from the Ecoinvent database V2.2 [53]. In bio-based chemicals production process, $\mathrm{CO}_{2}$ is emitted from pyrolysis, reaction and separation sections. The GHG emissions resulted in waste treatment, e.g. solid residual disposal and wastewater treatment are also considered and they are estimated based on the inventory data from Ecoinvent database V2.2 [53]. The organic carbon sequestered in biomass and the life cycle impacts of the production processes are allocated to products based on the mass basis. For simplicity, all carbon in bio-based chemicals is assumed to be released as carbon dioxide completely in their end use. The impacts of machinery, infrastructure and land use change are not included in our system boundary. 


\section{Results and discussions}

\subsection{Carbon conversion efficiency}

Fig. 4 shows the results for the carbon yield distributions. They suggest that Scenarios (2) and (5) are the most promising configurations from the carbon yield point of view. While Scenario (5) produces products of higher quality (less coke, COx and heavy ends), the quantity of the products is larger in Scenario (2) because it processes the whole crude bio-oil (WIBO and WSBO). As discussed in the flexibility optimization, Scenario (5) is more preferable for producing olefins. However, Scenario (2) produces more aromatics. Scenario (1) is the least efficient scenario as zeolite cracking, in the absence of hydrodeoxygenation, converts half of the bio-oil to coke. Scenario (3) has the lowest conversion efficiencies as it only processes WSBO and produces low quality products.

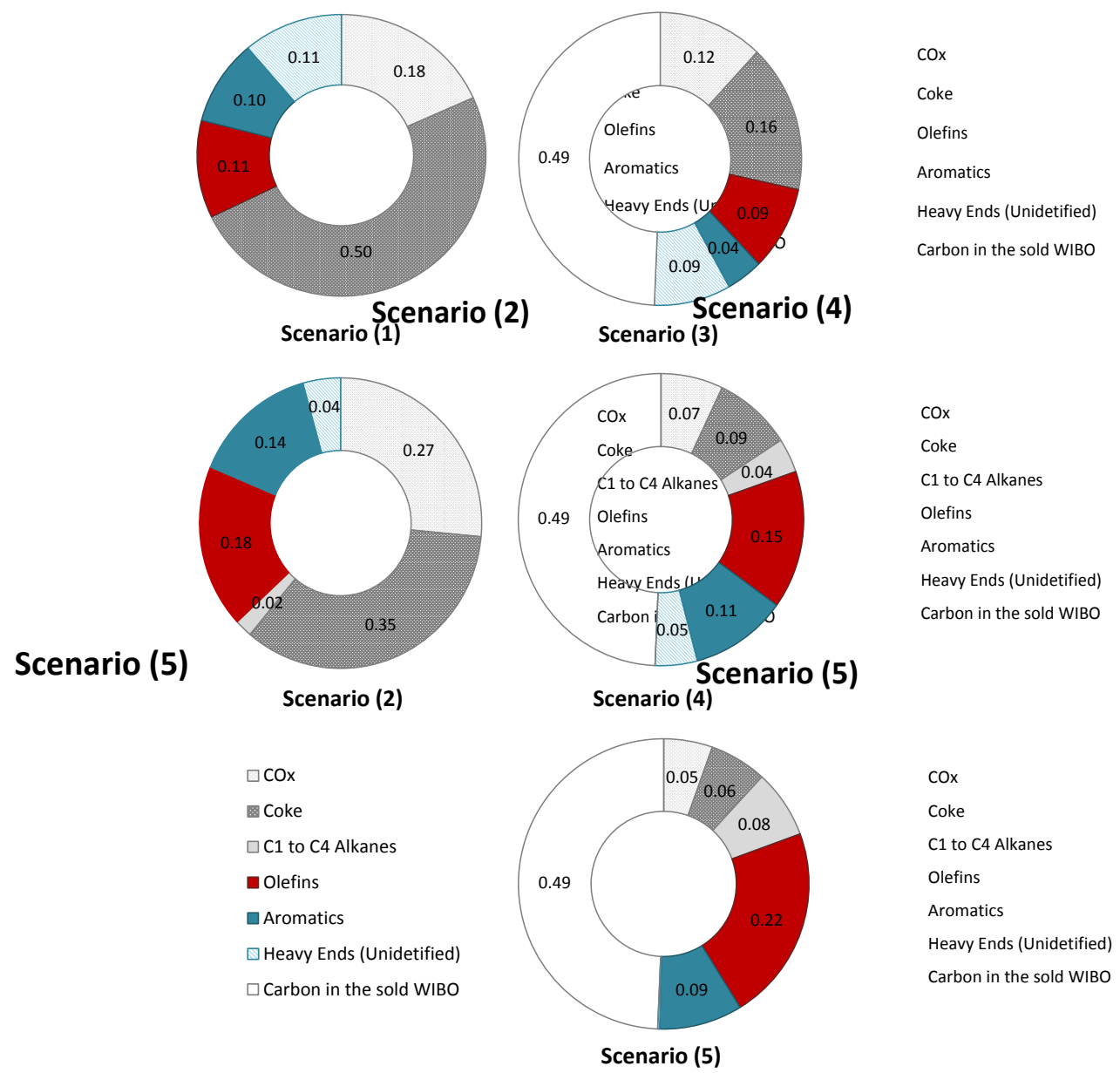

Fig. 4. The carbon yield distributions for scenarios 1-5 for different products

\subsection{Economic assessment}

Table 6 reports the net present values (NPVs) of the five scenarios. Since the process economy was found very sensitive to the price of hydrogen, a sensitivity analysis was performed for different hydrogen prices in the range of $1.5-12(\$ / \mathrm{kg})$ [7]. Table 6 shows that for a lower hydrogen price (1.5 $\$ / \mathrm{kg}$ ), Scenario (5) is the most profitable configuration. However, as the price of hydrogen increases 
(2.5-5 \$/kg), Scenario (2) becomes more attractive. The aforementioned results can also be presented in terms of internal rate of return (IRR) of each scenario, which is the rate of return that makes NPV equal to zero. Here, the calculated IRR values for the fifth scenario depend on the price of hydrogen and are $16.5 \%, 12.6 \%, 9 \%$ at hydrogen prices of $1.5 \$ / \mathrm{kg}$ and $2.5 \$ / \mathrm{kg}$ and $3.3 \$ / \mathrm{kg}$, respectively. Similar IRR values for the second scenario are $15.2 \% 14.4 \%, 13.7 \%$, respectively. These values are comparable with the studied scenarios by Zhang et al. [40], (7.6-13.3\%). The differences are due to various assumptions on biomass cost, fixed capital cost and economic assessment parameters etc. It is notable that only for high hydrogen prices ( $>5 \$ / \mathrm{kg}$ ), reforming the water insoluble bio-oil (WIBO) would be attractive, which should be attributed to the low hydrogen content of WIBO [54]. The IRR value for the fifth scenario with a reformer is $11.8 \%$.

Fig. 5 shows the results of break-down of the required capital investment for different section. The highest investment is needed for the pyrolysis section which processes a large amount of biomass. The value is similar for all scenarios. The capital requirement for the upgrading section depends on the number of reactors and the volume of the processed bio-oil. In that regard, Scenarios 2 and 5 are the most costly sections. The largest costs of the separation section belong to Scenario 2, due to a larger amount of reaction effluents (including $\mathrm{CO}_{2}$ ). The highest required capital investment belongs to Scenario $5 \mathrm{w} /$ reformer due to the additional processing step. Fig. 6 shows the breakdown of operating costs. The biomass feedstock is similar in all the scenarios. However, the costs of other feedstocks (Hydrogen/water/caustic) are highest for Scenario 2. Scenario 5 with the reformer requires the highest electricity costs for operating the air compressor, reformer fans, and air-coolers.

Table 6. Net present value (NPV) for different process configurations as a function of hydrogen price.

\begin{tabular}{|l|l|l|l|l|l|l|}
\hline H2 & \multicolumn{6}{|c|}{ NPV MM\$ } \\
\hline Price $(\mathbf{\$} / \mathbf{k g})$ & SC1 & SC2 & SC3 & SC4 & SC5 & SC5 w/ reformer \\
\hline 1.5 & -101.97 & $\mathbf{6 0 . 1 3}$ & -183.05 & -9.36 & $\mathbf{7 7 . 5 0}$ & $\mathbf{1 4 . 3 4}$ \\
\hline 2.5 & -102.22 & $\mathbf{4 7 . 8 1}$ & -183.28 & -45.67 & $\mathbf{2 2 . 4 7}$ & $\mathbf{1 4 . 3 4}$ \\
\hline 5 & -102.85 & $\mathbf{1 7 . 0 2}$ & -183.84 & -160.27 & -125.59 & $\mathbf{1 4 . 3 4}$ \\
\hline 7.5 & -103.47 & -13.78 & -184.39 & -298.01 & -333.07 & $\mathbf{1 4 . 3 4}$ \\
\hline 12 & -104.60 & -69.20 & -185.40 & -549.44 & -713.63 & $\mathbf{1 4 . 3 4}$ \\
\hline
\end{tabular}


Table 7. Minimum product Selling Price (MPSP) for different scenarios. These grey cells are more economic compared to the naphtha-based products in Table 5.

GHG emissions

\begin{tabular}{|l|l|l|l|l|l|l|}
\hline Product & SC1 & SC2 & SC3 & SC4 & SC5 & SC5 w/ reformer \\
\hline Ethane & 0.58 & $\mathbf{0 . 4 0}$ & 0.71 & 0.46 & $\mathbf{0 . 3 9}$ & $\mathbf{0 . 4 4}$ \\
\hline Benzene & 1.10 & $\mathbf{0 . 7 6}$ & 1.34 & 0.87 & $\mathbf{0 . 7 5}$ & $\mathbf{0 . 8 3}$ \\
\hline Toluene & 0.92 & $\mathbf{0 . 6 3}$ & 1.12 & 0.72 & $\mathbf{0 . 6 2}$ & $\mathbf{0 . 6 9}$ \\
\hline Butylene & 0.97 & $\mathbf{0 . 6 7}$ & 1.18 & 0.76 & $\mathbf{0 . 6 6}$ & $\mathbf{0 . 7 3}$ \\
\hline Ethylene & 1.93 & $\mathbf{1 . 3 3}$ & 2.35 & 1.52 & $\mathbf{1 . 3 1}$ & $\mathbf{1 . 4 6}$ \\
\hline Propylene & 2.05 & $\mathbf{1 . 4 1}$ & 2.49 & 1.61 & $\mathbf{1 . 3 9}$ & $\mathbf{1 . 5 4}$ \\
\hline Propane & 2.01 & $\mathbf{1 . 3 8}$ & 2.45 & 1.58 & $\mathbf{1 . 3 6}$ & $\mathbf{1 . 5 1}$ \\
\hline Butane & 1.14 & $\mathbf{0 . 7 8}$ & 1.39 & 0.90 & $\mathbf{0 . 7 7}$ & $\mathbf{0 . 8 6}$ \\
\hline Ethyl Benzene Styrene Xylene & 1.10 & $\mathbf{0 . 7 6}$ & 1.34 & 0.87 & $\mathbf{0 . 7 5}$ & $\mathbf{0 . 8 3}$ \\
\hline Indene+ Naphthalene & 1.46 & $\mathbf{1 . 0 0}$ & 1.77 & 1.14 & $\mathbf{0 . 9 9}$ & $\mathbf{1 . 1 0}$ \\
\hline WIBO & 0.00 & $\mathbf{0 . 0 0}$ & 0.03 & 0.02 & $\mathbf{0 . 0 2}$ & $\mathbf{0 . 0 2}$ \\
\hline
\end{tabular}

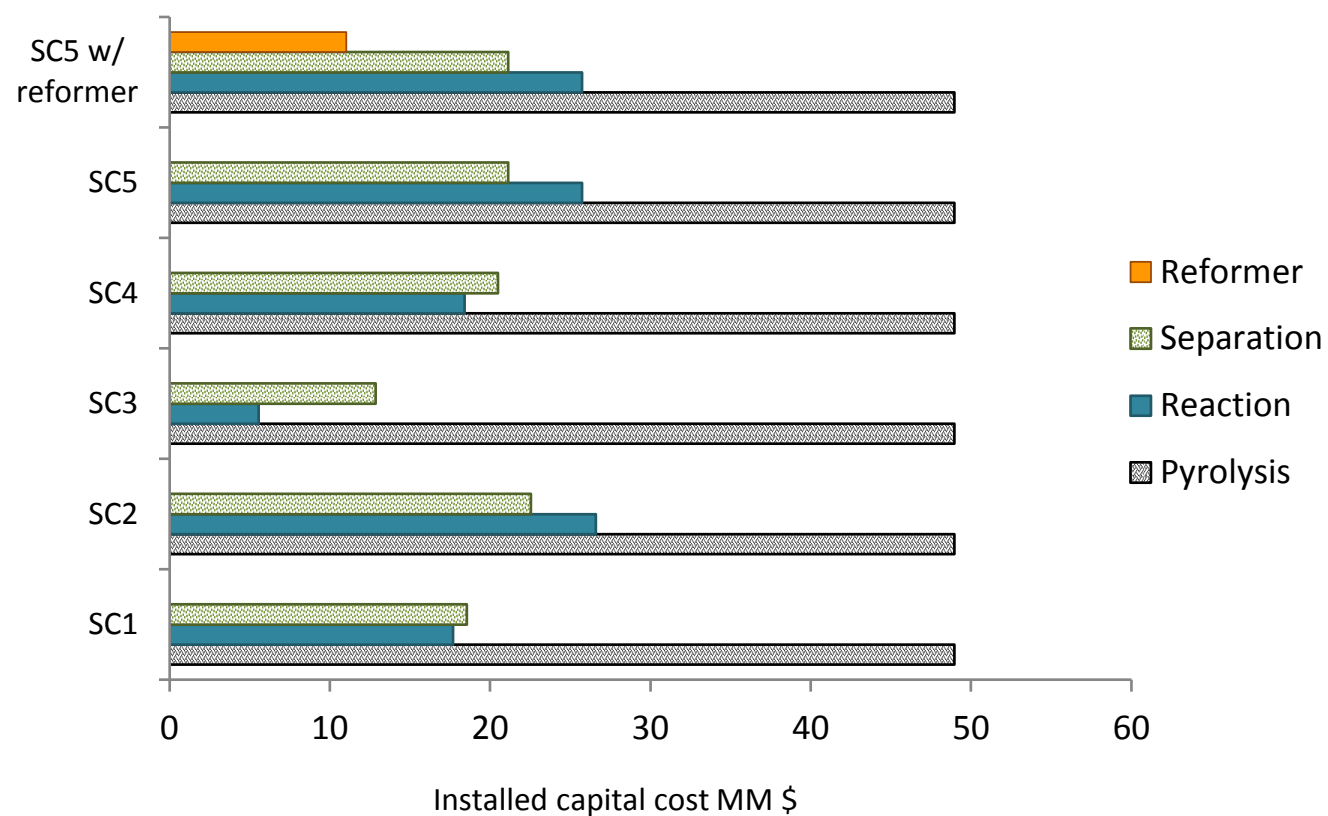

Fig. 5. The required capital investment for different processing for different scenarios.

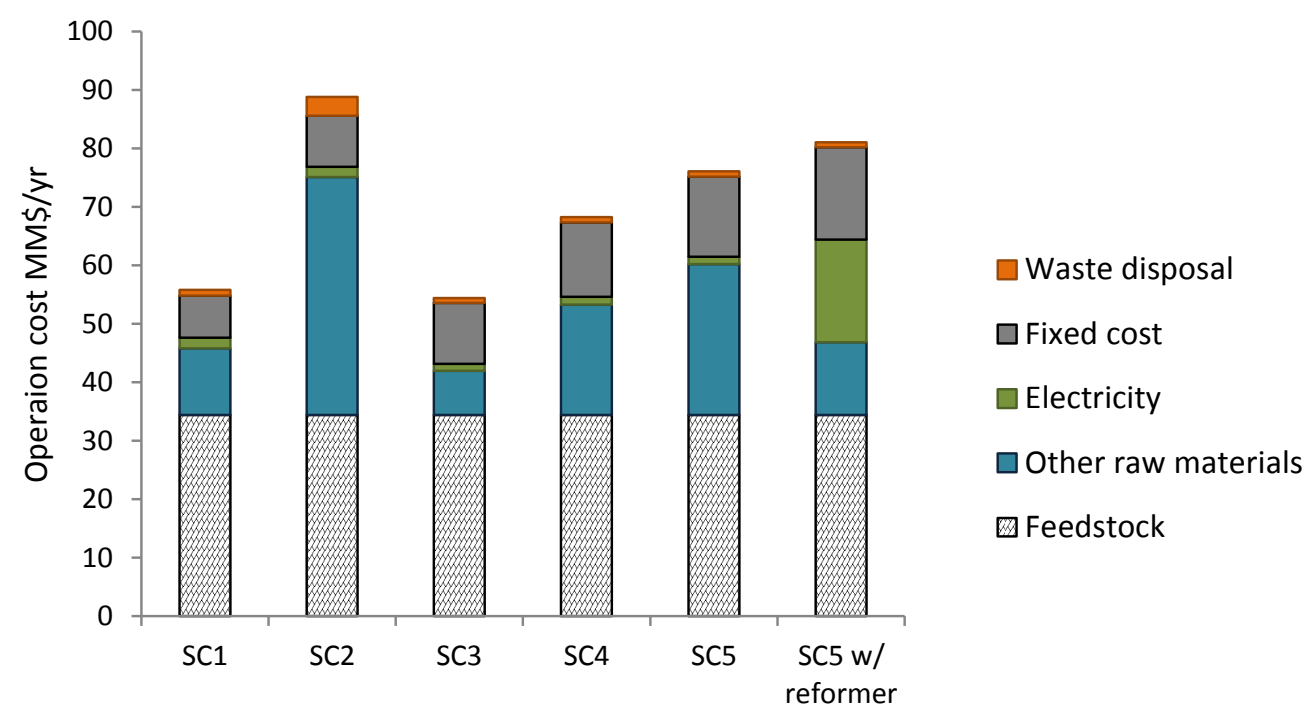

Fig. 6. The operating costs for different scenarios. 
Table 7 reports the minimum product selling prices (MPSPs) for Scenarios (1-5) based on cheap hydrogen $(1.5 \$ / \mathrm{kg})$ in addition to Scenario $5 \mathrm{w} /$ reformer, where WIBO is reformed for hydrogen production. These values are comparable with the prices of the petroleum-derived products in Table 5 . The competitive scenarios are Scenario 2 and Scenario 5. For example, the price of ethylene when derived from petroleum is $1.49 \$ / \mathrm{kg}$, (Table 4). By comparison, the price of ethylene in Scenarios 2, 5 and $5 \mathrm{w} /$ reformer are $1.33 \$ / \mathrm{kg}, 1.31 \$ / \mathrm{kg}, 1.46 \$ / \mathrm{kg}$, respectively.

The Table 8 lists the 'Cradle-to-Grave' GHG emissions for each bio-based chemical product. It shows that the Scenarios 2 delivers the lowest GHG emission factors for most of available products. This is due to exploitation of the whole bio-oil (WSBO and WIBO) rather than a fraction of it. Scenario 1 requires no natural gas or hydrogen but a large amount of steam, leading to higher GHG emission factors than those in Scenario 2 which is energy self-efficient. In general Scenario $5 \mathrm{~s}$ (with and without reformer) have higher GHG emission factors compared with other scenarios mainly due to their larger natural gas consumption for reforming WIBO.

Fig. 7 indicates the contribution results for GHG emissions of ethylene which is a main product in most of scenarios. The 'above-the-line' scores are environmental burdens while the 'below-the-line' ones are environmental credits. In our case, the 'below-the-line' scores are carbon sequestered in poplar biomass which is partially off-set by GHG emissions released in bio-based chemical production process and end use. Scenarios 1, 2 and $5 \mathrm{w} /$ reformer have the similar contributions whilst the other four share the similarity. This is because in Scenario 3-5 the total lifecycle impact is mainly allocated to WIBO due to its large amount of mass flow compared to other bio-based chemical products. Therefore the contribution of each process to the overall GHG emissions of ethylene is very small in Scenario 3-5. In Scenario 1, it is indicated that contributions by the poplar cultivation process (1.4\% of the environmental burdens), catalyst production $(0.05 \%)$, electricity $(0.1 \%)$, transport $(0.06 \%)$ and waste disposal $(0.4 \%)$ are negligible. The main contributors apart from end use are emissions to air (22\%) and steam production (7\%) from burning coke. Overall, Scenario 5 with the reformer delivers the best economic feasibility and is independence of fluctuations in hydrogen price; however, it has the worst GHG emissions performance. If the hydrogen price remain lower than 5 $\$ / \mathrm{kg}$, SC2 will become economically feasible (Table 6) and delivers the best GHG emissions performance among the five scenarios studied. 


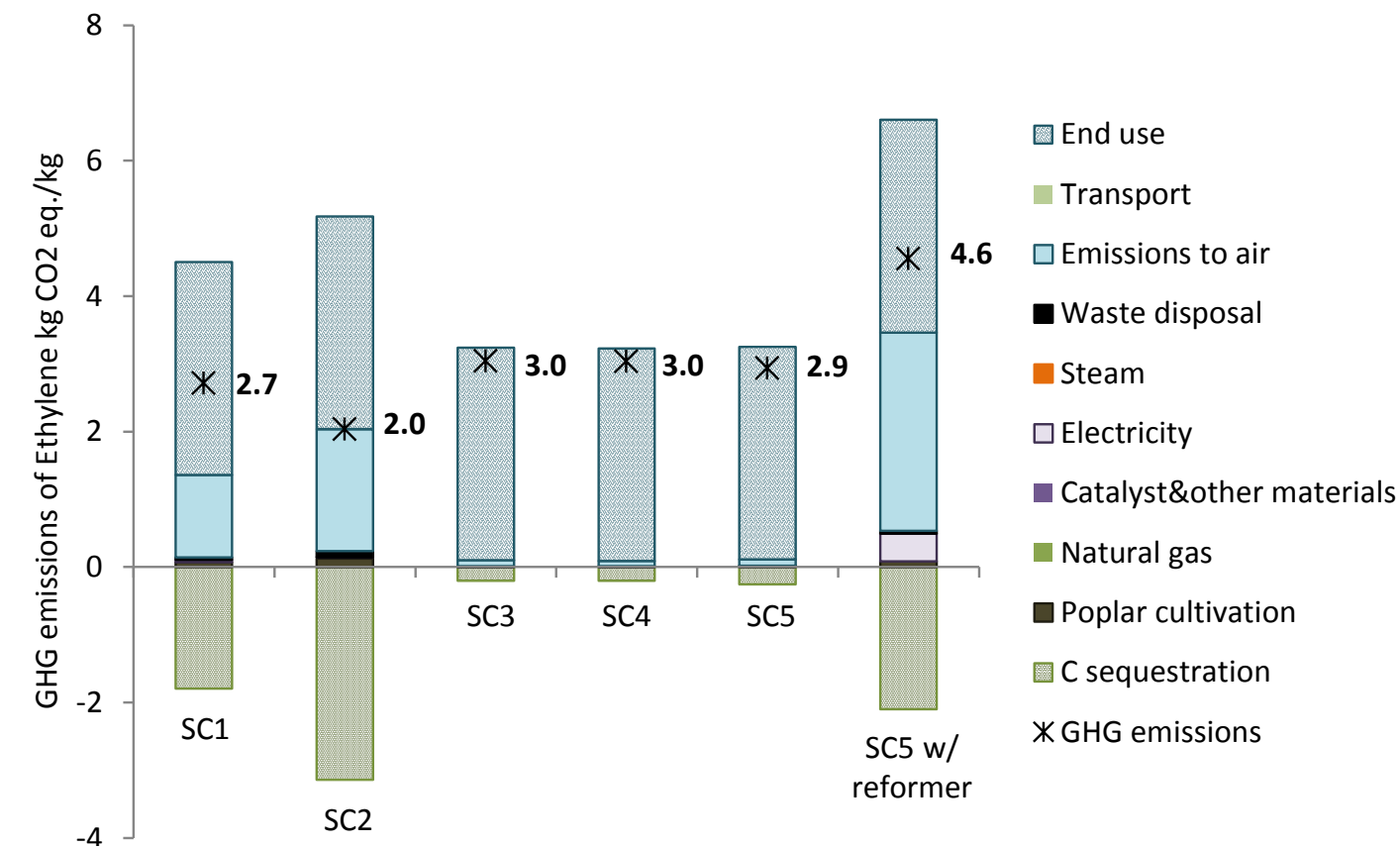

Fig. 7. Contribution analysis for GHG emissions of Ethylene in six scenarios (Functional Unit: 1kg, * indicates the GHG emission factors for Ethylene in each scenario)

Table 8 compares the GHG emissions of the six scenarios for the ethylene product with the GHG emissions of ethylene produced from naphtha, ethane, or biomass (wood, cassava, corn, and municipal solid waste). This table suggests that for example, ethylene production in the SC2 results in 44\% X\% lower GHG emissions, compared to the naphtha pathway, which should be attributed to the biogenic carbon sequestered in the biomass through photosynthesis process. In general, Table 9 suggests that the proposed pathway (pyrolysis followed by catalytic upgrading) features a better GHG footprint compared to other renewable pathways where biomass is firstly converted to ethanol, because their longer conversion processes involve enzyme usage as a large GHG emissions contributor.

Table 8. GHG emissions ( $\mathrm{kg} \mathrm{CO} 2 \mathrm{eq} . / \mathrm{kg})$ for each bio-based chemical product in six scenarios (Grey cells show the lowest GHG emissions for each bio-based chemical and bolded cell show the highest)

\begin{tabular}{|l|l|l|l|l|l|l|}
\hline g CO$_{2}$ equivalent/kg product & $\mathrm{SC} 1$ & $\mathrm{SC} 2$ & $\mathrm{SC} 3$ & $\mathrm{SC} 4$ & $\mathrm{SC} 5$ & SC5 w/ reformer \\
\hline Ethane & 0.00 & 2.90 & 0.00 & 2.94 & 2.90 & $\mathbf{3 . 3 9}$ \\
\hline Benzene & 3.27 & 3.13 & 3.36 & 3.34 & 3.31 & $\mathbf{3 . 8 6}$ \\
\hline Toluene & 3.07 & 2.77 & 3.30 & 3.24 & 3.22 & $\mathbf{4 . 2 2}$ \\
\hline Butylene & 3.04 & 2.90 & 3.11 & 3.10 & 3.05 & $\mathbf{3 . 7 7}$ \\
\hline Ethylene & 2.72 & 2.04 & 3.04 & 3.03 & 2.94 & $\mathbf{4 . 5 5}$ \\
\hline Propylene & 2.84 & 2.38 & 3.03 & 2.96 & 2.80 & $\mathbf{5 . 5 2}$ \\
\hline Propane & 0.00 & 2.97 & 0.00 & 3.00 & 2.97 & $\mathbf{3 . 4 3}$ \\
\hline Butane & 0.00 & 2.97 & 0.00 & 3.01 & 2.98 & $\mathbf{3 . 4 2}$ \\
\hline E-benzene, Styrene, Xylene & 3.12 & 2.63 & 3.30 & 3.32 & 3.27 & $\mathbf{3 . 7 4}$ \\
\hline Indene+ Naphthalene & 3.33 & 3.39 & 3.41 & 3.33 & 3.35 & $\mathbf{3 . 8 2}$ \\
\hline WIBO & 0.00 & 0.00 & 0.42 & 0.69 & 0.13 & $\mathbf{0 . 0 0}$ \\
\hline
\end{tabular}


Table 9. GHG emissions ( $\mathrm{kg} \mathrm{CO}$ eq./kg) for the ethylene product in six scenarios in comparison with other petroleum-based and biomass-based pathways.

\begin{tabular}{|c|c|c|c|}
\hline Feedstock & $\mathrm{CO}_{2} \mathrm{eq} \cdot \mathrm{g} / \mathrm{g}$ & Technology & Ref \\
\hline SC1 & 2.72 & Pyrolysis / upgrading & \\
\hline SC2 & 2.04 & Pyrolysis / upgrading & \\
\hline SC3 & 3.04 & Pyrolysis / upgrading & \\
\hline SC4 & 3.03 & Pyrolysis / upgrading & \\
\hline SC5 & 2.94 & Pyrolysis / upgrading & \\
\hline SC5 $\mathrm{w} /$ reformer & 4.55 & Pyrolysis / upgrading & \\
\hline Naphtha $^{(a)}$ & 3.63 & Hydrocracking & {$[1]$} \\
\hline Ethane $^{(a)}$ & 3.56 & Hydrocracking & [1] \\
\hline $\mathbf{M S W}^{(\mathbf{b})}$ & 4.9-12.6 & Fischer-Tropsch Gasification & [2] \\
\hline Ethanol (corn) & 3.81 & Enzymatic hydrolysis & [1] \\
\hline Ethanol (corn) & 3.4 & Enzymatic hydrolysis & {$[3]$} \\
\hline Ethanol (cassava) & 5.6 & Enzymatic hydrolysis & [3] \\
\hline Ethanol $(\text { wood })^{(c)}$ & $0.9-5.6$ & Enzymatic hydrolysis & [4] \\
\hline
\end{tabular}

(a) The GHG emissions reported in Ghanta et al.'s study [1] are for 'cradle-to-gate' ethylene production excluding the end use phase. In the present study, the 'cradle-to-grave' value was calculated by adding GHG emissions released in its end use by assuming that all carbon in ethylene is turned to carbon dioxide. (b) MSW refers to municipal solid waste. The variations reflect the different gasification technologies (i.e. Battelle, MTCI, and Choren). (c) The highest value represents the current technology whilst the lowest boundary represents the prospective technology with higher enzyme activity and lower enzyme loading in enzymatic hydrolysis of ethanol production.

\section{Conclusions}

The current state of industry is that many energy-intensive processes are relatively mature and the number of new processes that are being built is significantly less than the number of operating processes. This observation suggests that an important pathway toward decarbonisation of industrial processes is to substitute their feedstock with biomass-derived feedstocks and retrofit them using green technologies. The present paper proposed retrofitting a conventional olefin process by substituting its feedstock (naphtha) with bio-oil. Here, the enabling technology is the integrated catalytic bio-oil upgrading reactors which produce a mixture very similar to naphtha-based cracked gas. In the present research, it was shown that by using this technology, it is possible to retrofit current olefin processes to flexibly produce key olefins and aromatics. Furthermore, due to aforementioned synergies, retrofitting current olefin processes requires minimal changes in the separation network. The present paper also studied various process configurations, in which the whole bio-oil or only a fraction of it (only the water soluble part) is processed. It was shown that the profitability of the process may strongly depend on the hydrogen prices. For example, importing hydrogen for the prices over $6 \$ / \mathrm{kg}$ will results in bio-based chemicals which are generally more expensive than petroleumderived products. It was proposed that for hydrogen prices higher than $6 \$ / \mathrm{kg}$, water insoluble bio-oil (WIBO) could be reformed to produce the required hydrogen. From a GHG emissions point of view, the results concluded that there was a remarkable improvement of up to $44 \%$ reductions in the carbon footprint of the olefin process in certain scenarios.

The present research provided a proof of concept for decarbonisation of the olefin industries, based on lab-scale experimental data. We believe that the future research should be in the following directions: 
- Developing kinetic correlations for detailed reactor design, scale up and optimization,

- Evaluating the possibility of co-feeding bio-oil and conventional feedstocks (e.g., naphtha),

- Investigating the implication of retrofitting existing processes due to fouling and corrosion,

- Detailed design of control systems for the catalytic bio-oil upgrading reactors.

\section{Acknowledgements}

Dr Mahdi Sharifzadeh would like to thank the financial supports of the Carbon Trust (CT) and the Department of Energy \& Climate Change (DECC), UK, for his postdoctoral studies.

\section{References}

1. Ghanta M, Fahey D, Subramaniam B. Environmental impacts of ethylene production from diverse feedstocks and energy sources. Appl Petrochem Res, 2014; 4 (2): 167-179.

2. Nuss P, Gardner KH, Bringezu S. Environmental Implications and Costs of Municipal Solid WasteDerived Ethylene. J Ind Ecol, 2013; 17: 912-925.

3. Hong J, Zhang $\mathrm{Y}, \mathrm{Xu} \mathrm{X}, \mathrm{Li} \mathrm{X}$. Life cycle assessment of corn- and cassava-based ethylene production. Biomass Bioenergy, 2014; 67: 304-311.

4. Liptow C, Tillman A, Janssen M, Wallberg O, Taylor GA. Ethylene based on woody biomasswhat are environmental key issues of a possible future Swedish production on industrial scale. Int $\mathbf{J}$ Life Cycle Assess, 2013; 18: 1071-1081.

5. Xiang D, Qian Y, Man Y, Yang S. Techno-economic analysis of the coal-to-olefins process in comparison with the oil-to-olefins process. Appl Energy, 2014; 113: 639-647.

6. Demirbas MF. Biorefineries for biofuel upgrading: A critical review. Appl Energy, 2009; 86: S151-S161

7. Vispute TP, Zhang H, Sanna A, Xiao R, Huber GW. Renewable chemical commodity feedstocks from integrated catalytic processing of pyrolysis oils. Science, 2010; 330: 1222-1227.

8. Mettler MS, Vlachos DG, Dauenhauer PJ, Energy Environ. Sci., 2012; 5: 7797.

9. Azeez AM, Meier D, Odermatt J, Willner T. Fast Pyrolysis of African and European Lignocellulosic Biomasses Using Py-GC/MS and Fluidized Bed Reactor. Energy Fuels, 2010; 24 : 2078-2085.

10. Ben H, Ragauskas AJ. NMR Characterization of Pyrolysis Oils from Kraft Lignin. Energy Fuels, 2011; 25: 2322-2332.

11. Ben H, Ragauskas AJ. Comparison for the compositions of fast and slow pyrolysis oils by NMR 
Characterization. Bioresour Technol, 2013; 147: 577-584.

12. White JE, Catallo WJ, Legendre BL. Biomass pyrolysis kinetics: A comparative critical review with relevant agricultural residue case studies. J Anal Appl Pyrol, 2011; 91: 1-33.

13. Papadikis K, Gu S, Bridgwater AV, Gerhauser H. Application of CFD to model fast pyrolysis of biomass. Fuel Process Technol, 2009; 90: 504-512.

14. Isahak WNRW, Hisham MWM, Yarmo MA, Hin TY. A review on bio-oil production from biomass by using pyrolysis method. Renew. Sust. Energ. Rev., 2012; 16: 5910-5923.

15. Motasemi F, Afzal MT. A review on the microwave-assisted pyrolysis technique. Renew. Sust. Energ. Rev., 2013, 28, 317-330.

16. Borges FC, Du Z, Xie Q, Trierweiler JO, Cheng Y, Wan Y, Liu Y, Zhu R, Lin X, Chen P, Ruan R. Fast microwave assisted pyrolysis of biomass using microwave Absorbent. Bioresour Technol, 2014; 156: 267-274.

17. Akhtar J, Amin NS. A review on operating parameters for optimum liquid oil yield in biomass pyrolysis. Renew. Sust. Energ. Rev., 2012; 16: 5101-5109.

18. Zhang L, Liu R, Yin R, Mei Y. Upgrading of bio-oil from biomass fast pyrolysis in China: A review. Renew Sust Energ Rev, 2013; 24: 66-72.

19. Sadhukhan J. Multiscale simulation for high efficiency biodiesel process intensification. Computer Aided Chemical Engineering, 2012; 30: 1023-1027.

20. Brown TR, Thilakaratne R, Brown RC, Hu G. Techno-economic analysis of biomass to transportation fuels and electricity via fast pyrolysis and hydroprocessing. Fuel, 2013; 106: $463-$ 469.

21. Zhu Y, Biddy MJ, Jones SB, Elliott DC, Schmidt AJ. Techno-economic analysis of liquid fuel production from woody biomass via hydrothermal liquefaction (HTL) and upgrading. Appl Energy, 2014; 129: 384-394.

22. Gebreslassie BH, Slivinsky M, Wang B, You F. Life cycle optimization for sustainable design and operations of hydrocarbon biorefinery via fast pyrolysis, hydrotreating and hydrocracking. Comput Chem Eng, 2013; 50: 71-91.

23. Kim J, Realff MJ, Lee JH, Whittaker C, Furtner L. Design of biomass processing network for biofuel production using an MILP model. Biomass Bioenerg, 2011; 35: 853-871.

24. Akgul O, Shah N, Papageorgiou LG. Economic optimisation of a UK advanced biofuel supply chain Economic optimisation of a UK advanced biofuel supply chain. Biomass Bioenerg, 2012; 41: $57-72$. 
25. Braimakisa K, Atsoniosa K, Panopoulos KD, Karellas S, Kakaras E, Economic evaluation of decentralized pyrolysis for the production of bio-oil as an energy carrier for improved logistics towards a large centralized gasification plant. Renew. Sust. Energ. Rev., 2014; 35: 57-72.

26. Meier D, Beld B, Bridgwater AV, Elliott DC, Oasmaa A, Preto F. State-of-the-art of fast pyrolysis in IEA bioenergy member countries. Renew Sust Energ Rev, 2013; 20: 619-641.

27. Saidi M, Samimi F, Karimipourfard D, Nimmanwudipong T, Gates BC, Rahimpour MR. Upgrading of lignin-derived bio-oils by catalytic hydrodeoxygenation. Energy Environ. Sci., 2014, 7, 103-129. Energy Environ. Sci., 2011, 4, 985.

28. Baker EG, Elliott DC. Catalytic upgrading of biomass pyrolysis oils, Elsevier Appl Sci Publ Ltd, Barking Essex, 1988, pp. 883-895.

29. Demirbas A. Competitive liquid biofuels from biomass. Appl Energy, 2011; 88: 17-28

30. Ibáñez M, Valle B, Bilbao J, Gayubo AG, Castaño P, Effect of operating conditions on the coke nature and HZSM-5 catalysts deactivation in the transformation of crude bio-oil into hydrocarbons. Catalysis Today, 2012; 195 (1): 106-113.

31. Xiu S, Shahbazi A. Bio-oil production and upgrading research: A review. Renew. Sust. Energ. Rev., 2012; 16: 4406-4414.

32. Taarning E, Osmundsen CM, Yang X, Voss B, Andersen SI, Christensen CH. Zeolite-catalyzed biomass conversion to fuels and chemicals. Energy Environ. Sci., 2011; 4: 793-804.

33. Ragauskas J, Williams CK, Davison BH, Britovsek G, Cairney J, Eckert CA, Frederick Jr WJ, Hallett JP, Leak DJ, Liotta CL, Mielenz JR, Murphy R, Templer R, Tschaplinski T. The Path Forward for Biofuels and Biomaterials. Science, 2006; 311: 484-489.

34. Peterson AA, Vogel F, Lachance RP, Froling M, Antal Jr. MJ, Tester JW. Thermochemical biofuel production in hydrothermal media: A review of sub- and supercritical water technologies. Energy Environ. Sci., 2008; 1: 32-65.

35. Ruiz JCS, Dumesic JA. Catalytic routes for the conversion of biomass into liquid hydrocarbon transportation fuels. Energy Environ. Sci., 2011, 4, 83.

36. Jones SB, Holladay JE, Valkenburg C, Stevens DJ, Walton CW, Kinchin C, Elliott DC, Czernik S. Production of Gasoline and Diesel from Biomass via Fast Pyrolysis, Hydrotreating and Hydrocracking: A Design Case, U.S. Department of Energy. 2009, Technical Report.

37. Wright MM, Daugaard DE, Satrio JA, Brown RC, Techno-economic analysis of biomass fast pyrolysis to transportation fuels. Fuel, 2010; 89 (1): S2-S10.

38. Shemfe MB, Panneerselvam Ranganathan SG, Techno-economic performance analysis of biofuel production and miniature electric power generation from biomass fast pyrolysis and bio-oil 
upgrading, Fuel, 2015; 143: 361-372.

39. Brown TR, Zhang Y, Hu G, Brown RC. Techno-economic analysis of biobased chemicals production via integrated catalytic processing. Biofuels, Bioprod. Bioref. 2012; 6: 73-87.

40. Zhang Y, Brown TR, Hu G, Brown RC, Techno-economic analysis of two bio-oil upgrading pathways, Chemical Engineering Journal, 2013; 225: 895-904.

41. Jenkins BM, Baxter LL, Miles Jr. TR, Miles TR. Combustion properties of biomass. Fuel processing technology, 1998; 54: 17-46.

42. Sharifzadeh M, Rashtchian D, Pishvaie MR, Thornhill NF. Energy induced separation network synthesis of an olefin compression section: a case study. Ind Eng Chem Res, 50; 3: 1610-1623.

43. Othmers K. Encyclopedia of Chemical Technology, 4th ed.; Wiley: New York, 1998.

44. Sipila K, Kuoppala E, Fagernas L, Oasmaa A, Characterization of biomass-based Flash pyrolysis oils, Biomass Bioenergy, 1998; 14: 103-113.

45. Vispute TP and Huber GW. Production of hydrogen, alkanes and polyols by aqueous phase processing of wood-derived pyrolysis oils. Green Chem., 2009; 11: 1433-1445.

46. Phillips S, Aden A, Jechura J, Dayton D, T Eggeman. 2007, National Renewable Energy Laboratory (NREL), Thermochemical Ethanol via Indirect Gasification and Mixed Alcohol Synthesis of Lignocellulosic Biomass, Technical Report, NREL/TP-510-41168.

47. US Energy Information Administration, Natural Gas Prices, URL:http://www.eia.gov/dnav/ng/ng_pri_sum_dcu_nus_a.htm , accessed August 2014

48. US Energy Information Administration, Electricity Wholesale Market, Data, URL: http://www.eia.gov/electricity/wholesale/ , accessed August 2014.

49. Davis R, Aden A, Pienkos PT. Techno-economic analysis of autotrophic microalgae for fuel production. Appl Energy, 2011; 88: 3524-3531.

49. Aspen Plus software tool, V8.4. Apsen Tech.

50. Ethane spot price. URL:http://www.platts.com/news-feature/2013/petrochemicals/globalmargins/us natgas, accessed August 2014.

51. US Energy Information Administration, Natural gas liquids prices, 2013b, URL:http://www.eia.gov/todayinenergy/detail.cfm?id=12291, accessed August 2014.

52. Gasol CM, Gabarrell X, Anton A, Rigola M, Carrasco J, Ciriae P, Rieradevall J. LCA of poplar bioenergy system compared with Brassica carinata energy crop and natural gas in regional scenario. Biomass Bioenerg, 2009; 33: 119-129.

53. Jungbluth N, Faist Emmenegger M, Dinkel F, Stettler C, Doka G, Chudacoff M, Dauriat A, 
Gnansounou E, Sutter J, Spielmann M, Kljun N, Keller M, Schleiss K. Life cycle inventories of Bioenergy. 2007, Swiss Centre for Life Cycle Inventories, Dübendorf.

54. Marker, TL 2005, Opportunities for biorenewables in oil refineries. Final Technical Report. United States. DOEGO15085, UOP, Des Plaines, IL. 


\section{Graphical Abstract}
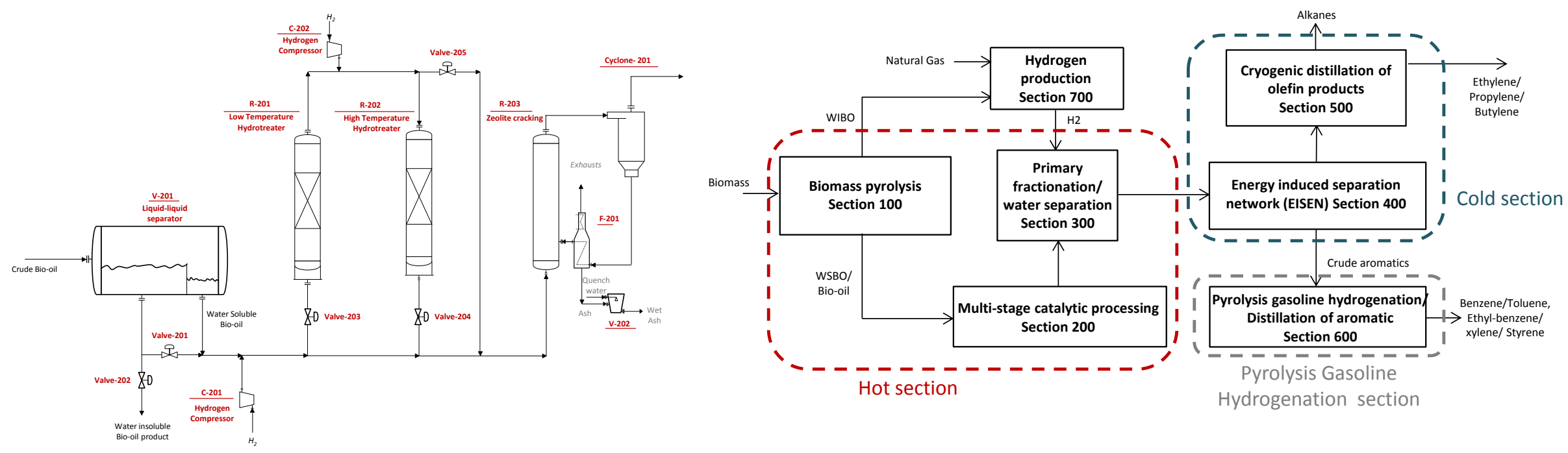

Decarbonisation of conventional olefin processes by integrated catalytic processing of biomass pyrolysis oil 